\title{
The Impacts of Morphology of Traditional Alleys on Thermal comfort: A case study of Da Long Wang Xiang in Zhenjiang, China
}

\author{
Cen CHEN $^{1}$, Lu DING ${ }^{2}$, Yuhan ZHANG ${ }^{1}$, Hainan QIU ${ }^{3}$, Yingnan $\mathrm{LI}^{1, *}$ \\ ${ }^{1}$ Department of Environmental Design, School of Arts, Jiangsu University, Zhenjiang, Jiangsu, 212013, China \\ ${ }^{2}$ Department of Computer Graphics Technology, Purdue University, West Lafayette, Indiana, 47907, USA \\ ${ }^{3}$ Jiangsu Urban Planning and Design Group Co., Ltd, Nanjing, 210036, Jiangsu, China
}

\begin{abstract}
Traditional alleys in China are mostly characterized by dense population, poor infrastructure, and narrow streets. The general renewal approaches of traditional alleys paid more attention to the physical space while they lack consideration for the thermal comfort of residents, which often results in declines in the rational design of the space and vitality of the community. This research takes Da Long Wang Xiang historical district in Zhenjiang as a case study to investigate the relationship between the morphology of street spaces (Alley Width (W), Sky View Factor (SVF), Height to Width Ratio (H/W), building height on both sides of alley) and microclimatic parameters, such as Potential Air Temperature (Ta), Relative Humidity (RH), Wind Speed (WS), Mean Radiation Temperature (Tmrt) and Physiological Equivalent Temperature (PET). The results have shown that: 1) the peak temperature was found at 14:00, and the thermal comfort of all alleys is overheated during this period, particularly NW-SE alleys are hotter than NESW alleys; 2) the deviation of Ta, RH, WS, and Tmrt among the NW-SE alleys during 13:00 to 15:00 are smaller than those among the NE-SW alleys; and 3) set a shading device or higher buildings on the side of the afternoon solar incidence can help to create a more comfortable thermal comfort. The findings of this research will provide a new strategy for the renewal design of traditional alleys.
\end{abstract}

\section{Introduction}

Traditional alleys are important elements of the Chinese historical areas, and they are also one of the main outdoor spaces for urban residents' activities and residence. However, with the rapid development of the urban areas, many Chinese traditional alleys have not been updated. It leads to many problems in these areas, such as dense population, poor infrastructure, and deterioration of the public spaces. Particularly, such alleys became an area of frequent high temperature in summer because of the narrow spaces and lack of greenery, which decreases the quality of life, and further threatening the health and wellbeing of building occupants ${ }^{[1]}$. The frequencies of extremely high temperatures result in increased heat-related mortality ${ }^{[2-}$ 4]. Studies have shown that elderly populations are among the most vulnerable to heatwaves and elevated temperatures ${ }^{[5]}$. Therefore, improving the thermal environment of traditional alleys is regarded as one of the most important research topics in urban renewal.

The urban morphology can directly affect the energy exchange process between the atmosphere and the underlying surfaces within the urban canopy layer, creating various thermal environments at a small scale, namely microclimate ${ }^{[6]}$. The microclimate correlated with human thermal comfort. It is also widely concerned by landscape designers in the past two decades since its scale is easy to handle and strongly affected by landscape design. However, previous studies related to traditional alleys in China mainly focus on the thermal comfort assessment of the historical districts which have been transformed from the dwelling to commercial street by urban renewals, for instance, Gao Chun old street and Lao Men Dong historical areas in Nanjing, Sanxuejie historical and cultural areas in Xi 'an, Fu Rong-Bai Hua Zhou historical areas in Jinan Shandong province, and historical street Hutong in Beijing [7-11]. The public spaces in these historic areas have improved by increasing open spaces, greening, water bodies, and landscape facilities, thereby mitigating the heat stress. Yet, fewer studies focus on the thermal comfort of traditional areas with a residential function.

Da Long Wang Xiang (DLWX) is planned as a region for protection and preservation since 2017 based on the "Zhenjiang Da Long Wang Xiang Historical and Cultural Areas Protection Planning" published by the Zhenjiang government. However, the environment has not improved as the urban renewal in this area lags, which results in a loss of young and middle-aged population. Now, the elderly and urban low-income people are the main residents of this area, as the proportion of the elderly is $68.4 \%^{[12]}$. According to the on-site observation, we found older people prefer to cool

\footnotetext{
* Corresponding author: lyn48512@hotmail.com
} 
off in the outdoor spaces, therefore, improving the thermal comfort of alleys space can increase their utilization and further enhance the vitality of those areas. Thus, this paper takes DLWX as a case study to investigate the impacts of its morphology on thermal comfort. The findings of this study may provide a theoretical reference for improving the thermal comfort in this area and further promote the development of the green and low-carbon community.

\section{Case study}

\subsection{Study site}

DLWX locates in the old city centre of Zhenjiang City $\left(31^{\circ} 37\right.$ ' 32 $19^{\prime} \mathrm{N}, 118^{\circ} 58$ ' 119॰58' E), Jiangsu Province, China. It is an area concentrated with a large number of Zhenjiang's vernacular dwellings and other historic buildings in the late Qing Dynasty and the early periods of the Republic of China. Zhenjiang has a humid subtropical climate with four distinct seasons. The average annual temperature is $15.6{ }^{\circ} \mathrm{C}$, and the precipitation is $1088.2 \mathrm{~mm}$. According to climate data statistics from 2010 to $2019^{[13]}$, the hottest months are mainly in July and August, and the maximum temperature is $40.2^{\circ} \mathrm{C}$.

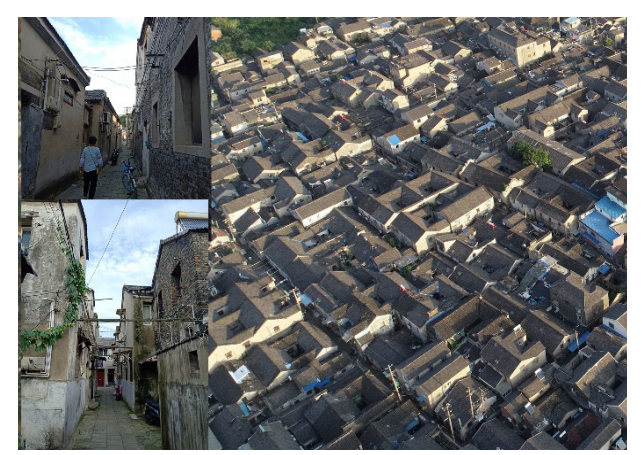

Fig. 1. An aerial and on-site photograph of DLWX.

\subsection{Morphology of alleys}

DLWX has a typical grid street and alley spatial texture, in which the main orientation of the alleys is: Northeast to Southwest (NE-SW) and Northwest to Southeast (NW-SE). The alleys were classified into three types in terms of width: I) wide alley, generally between 3.5 and $4 \mathrm{~m}$, up to 5-6 m; II) moderate alley, between 2.5 and $3.5 \mathrm{~m}$, which is the most common type of alleys in the area, and III) fine alley, which is less than $2.5 \mathrm{~m}$, the narrowest valley is only $1.5 \mathrm{~m}$ in width (see Table 1 and Fig. 2).

Table 1. The classification of alleys based on alley width in DLWX.

\begin{tabular}{ll}
\hline Alley & Average width \\
\hline I & $3.5-4 \mathrm{~m}$, up to $5 \mathrm{~m}$ at widest place \\
II & $\begin{array}{l}2.5-3.5 \mathrm{~m} \text {, the most common alley type in this } \\
\text { block }\end{array}$ \\
III & Less than $2.5 \mathrm{~m}$, the narrowest place is only $1.5 \mathrm{~m}$ \\
\hline
\end{tabular}

The building heights are $3-5 \mathrm{~m}$ for a one-story residence, $6-7 \mathrm{~m}$ for a 2-story residence, and 8-9 $\mathrm{m}$ for a 3 -story residence. The specific distribution of the classification is shown in Fig. 2, and the characteristic parameters of typical alleys for simulation are shown in Table 2.

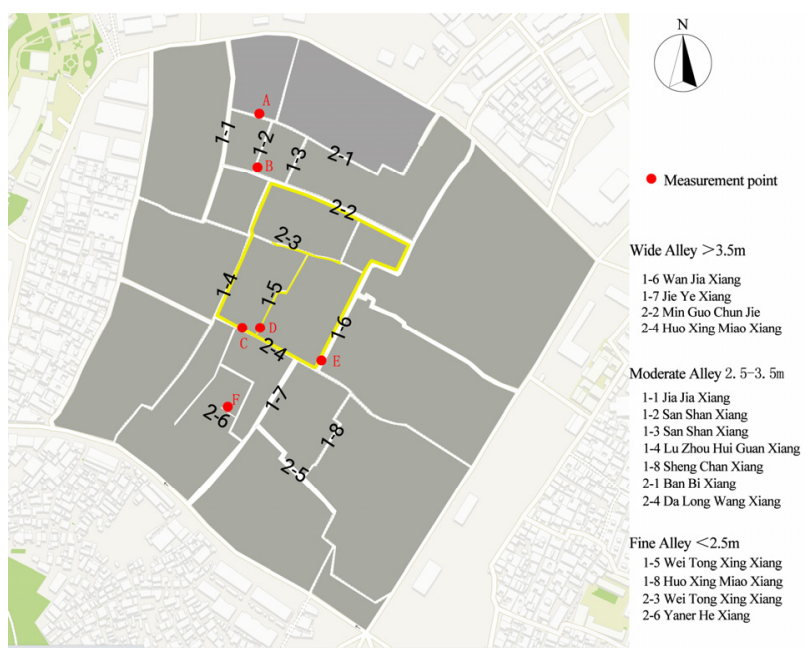

Fig. 2. Study site. The yellow lines and red dots on the map are selected typical alleys and measure points, respectively.

Table 2. Characteristic parameters of typical alleys.

\begin{tabular}{lllll}
\hline No. & AW & $\mathbf{W}_{\max }$ & $\mathbf{W}_{\min }$ & $\mathbf{H} / \mathbf{W}$ \\
\hline $2-4$ & 3.32 & 5.3 & 2.5 & $0.4-2.0$ \\
$2-2$ & 3.5 & 4.72 & 2.3 & $0.7-3.5$ \\
$2-3$ & 2.1 & 2.39 & 1.86 & $1.7-3.8$ \\
$1-4$ & 3 & 2.98 & 2.3 & $1.4-3.0$ \\
$1-6$ & 3.8 & 5.3 & 2.8 & $0.8-4.3$ \\
$1-5$ & 2.0 & 2.75 & 1.36 & $2-4.5$ \\
\hline
\end{tabular}

* AW: average alley width, $\mathrm{W}_{\text {max }}$ : maximum width, Wmin: minimum width, H/W: Height to Width Ratio.

\section{Methodology}

\subsection{On-site Measurement}

Six sample points were selected for on-site measurement at different types of space according to the different orientations and widths in DLWX (see Fig. 2). The onsite measurement was conducted on 18th August 2020 with less cloud and wind. The experimental equipment includes a Watchdog 2900E Mini-stations (Spectrum Technologies USA Inc., USA), 6 TR-72wf Thermo Recorders ( $\mathrm{T} \& \mathrm{D}$ Corporation, Japan). The Watchdog was set at a high platform 10 meters nearby the study site, TR-72wfs were mounted at 1.5-meter-high at $1 \mathrm{~min}$ intervals. In addition, a rangefinder was used to measure the width of the selected alleys and the building heights on both sides for model construction. 


\subsection{Model simulation}

The 3D model of the selected alleys was built according to the field survey and the example of the modelling alley in ENVI-met is shown in Fig.3. The meteorological data collected by Watchdog as boundary conditions were input into ENVI-met for the simulation, and simulated time is 12 hours covering from 7:00 to 19:00. The model validation was conducted by comparing the simulated data and the measured data at the fixed points. The parameters of the set boundary conditions are shown in Table 3.

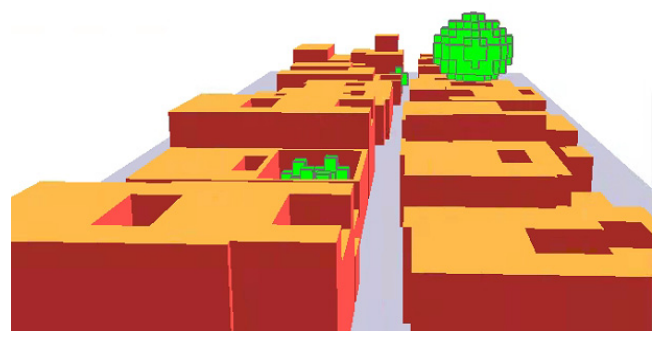

Fig.3. A 3D model of alley 2-4 in ENVI-met

Table 3. Initial parameter setting.

\begin{tabular}{ll}
\hline Parameter & Input value \\
\hline Start time & $7: 00$ \\
simulation time(h) & 12 \\
initial wind speed $(\mathrm{m} / \mathrm{s})$ & 2.2 \\
initial direction of wind & 240 \\
Roughness $\left({ }^{\circ}\right)$ & 0.010 \\
Initial Ta $\left({ }^{\circ} \mathrm{C}\right)$ & 28.48 \\
Initial RH $(\%)$ & 45.21 \\
\hline
\end{tabular}

\subsection{Data analysis}

The simulated data were used to analyze the relationship between microclimate parameters (i.e., Potential Air Temperature $\left(\mathrm{Ta},{ }^{\circ} \mathrm{C}\right)$, Relative Humidity $(\mathrm{RH}, \%)$, Wind Speed (WS, m/s), Mean Radiation Temperature $\left(\right.$ Tmrt, ${ }^{\circ} \mathrm{C}$ ) and Spatial morphological indexes (i.e., Width (W), Sky View Factor (SVF), aspect ratio (height to width ratio, $\mathrm{H} / \mathrm{W}$ ), and building height on both sides of the alley (Fig. 4). Physiological Equivalent Temperature $\left(\mathrm{PET},{ }^{\circ} \mathrm{C}\right)$ was selected as the thermal comfort evaluation index in this paper, which is particularly suitable for outdoor thermal comfort analysis and has been widely applied in human-biometeorology studies in areas with various climates ${ }^{[14]}$. SVF is a commonly used indicator for describing urban geometry to calculated as the ratio of the unobstructed parts, the value between 0 (sky completely obstructed) and 1 (sky completely visible $)^{[7,15]}$.

Table 4. R-correlation value and RMSE.

\begin{tabular}{llllll}
\hline $\mathrm{Ta}$ & $\mathrm{R}^{2}$ & $\mathrm{RMSE}\left({ }^{\circ} \mathrm{C}\right)$ & $\mathrm{RH}$ & $\mathrm{R}^{2}$ & $\mathrm{RMSE}(\%)$ \\
\hline $\mathrm{A}$ & 0.9581 & 0.86 & $\mathrm{~A}$ & 0.8731 & 7.43 \\
$\mathrm{~B}$ & 0.9686 & 0.68 & $\mathrm{~B}$ & 0.9667 & 4.81 \\
$\mathrm{C}$ & 0.9848 & 0.65 & $\mathrm{C}$ & 0.9261 & 3.2 \\
$\mathrm{D}$ & 0.9341 & 0.85 & $\mathrm{D}$ & 0.9181 & 5.13 \\
$\mathrm{E}$ & 0.9722 & 0.56 & $\mathrm{E}$ & 0.9195 & 5.19 \\
$\mathrm{~F}$ & 0.9154 & 0.95 & $\mathrm{~F}$ & 0.9012 & 5.01 \\
\hline
\end{tabular}

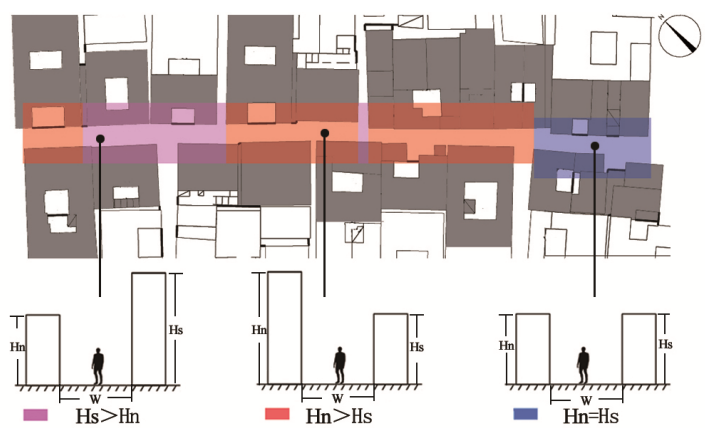

Fig.4. Cross-sections of NW-SE alley in DLWX.

\section{Results and discussion}

\subsection{Validation of the simulation}

In order to verify the simulated results, we calculate the statistical correlation between on-site measurement data and the simulated data on each sample point. The SPSS 26.0 (IBM Corp., New York, USA) analytical software is used to calculate the R-correlation value. Furthermore, the accuracy of the simulated results was evaluated based on the root square error (RMSE). The $\mathrm{R}^{2}$ and RMSE values are shown in Table 4. According to previous studies ${ }^{[16]}$, the errors between the simulated data and the measured data in this study are acceptable.

\subsection{Thermal comfort of alleys with different orientations}

Fig. 5 shows the distribution of the air temperature of the typical alleys at 14:00 that the peak air temperature detected. It found that the area of high temperature in NW-SE alleys is larger than that in NE-SW alleys, whiles the area of high temperature in fine alleys is smaller than that in wide alleys.

We further analysed the average microclimate parameters from 13:00 to 15:00 (see Fig. 6). We found that the average Ta of NW-SE alleys at the three hours are generally higher than those of NE-SW alleys, whiles the RH shows an opposite trend. The error bars show the lowest and highest limit of these values. The Ta difference among the NW-SE alleys with different widths is smaller than that of NE-SW alleys at those three hours because the orientation of the NW-SE alley is more aligned to the motion direction of the sun, thereby less shielding on the east and west sides. Therefore, the role of sun irradiation is more important in affecting the Ta. Due to the higher temperature, the RH of NW-SE alleys is always lower than that of NESW alleys. The RH difference among the NW-SE alleys with different widths is small, while that among the different NE-SW alleys is more obvious. Although there is little difference in the mean wind speed of alleys with different directions, the difference among the NW-SE alleys with different widths is significantly smaller than that among the NE-SW alleys. Tmrt of NW-SE alleys reaches the peak value at 14:00, while that of NE-SW alleys reaches the peak at 13:00, then decrease afterward. 
In general, the MRT of NE-SW alleys is lower than that
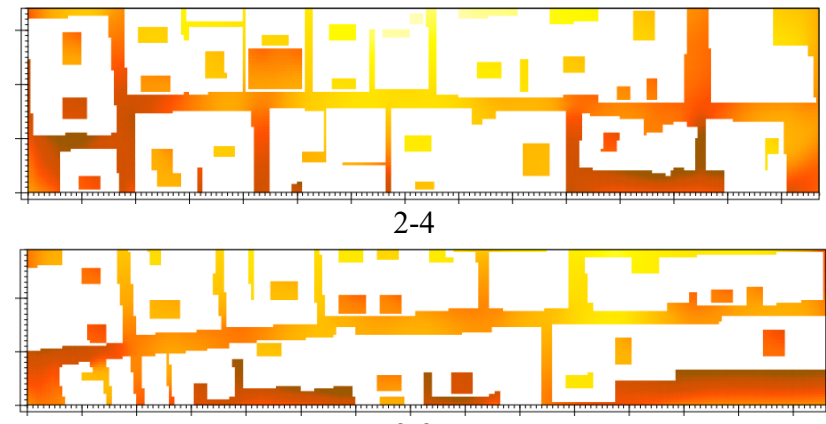

$2-2$

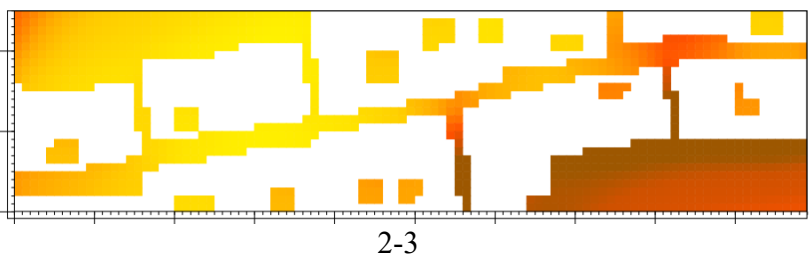

of NW-SE alleys.
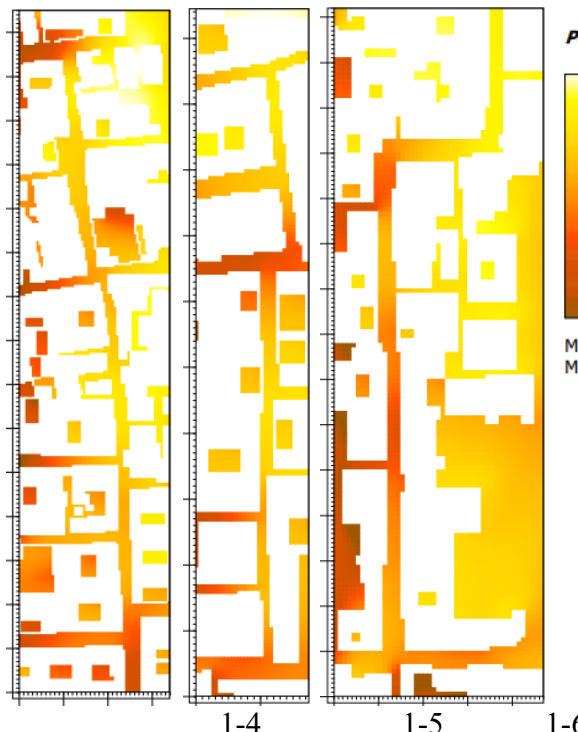

Potential Air Temperature

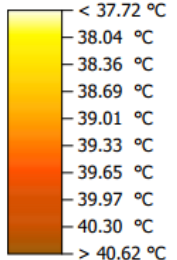

Min: $37.74^{\circ} \mathrm{C}$

Max: $40.96^{\circ} \mathrm{C}$

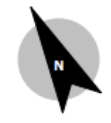

Fig. 5. Potential Air Temperature (Ta) distribution map at 14:00 pm. NW-SE alley: 2-4, 2-2, 2-3 ; NE-SW alley:1-4,1-5,1-6.

a.

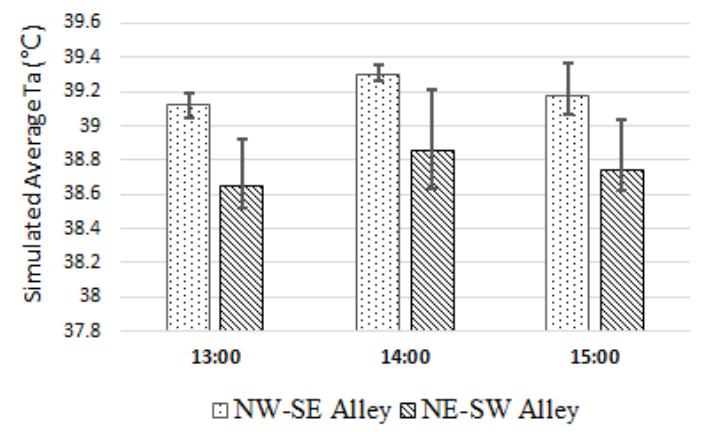

c.

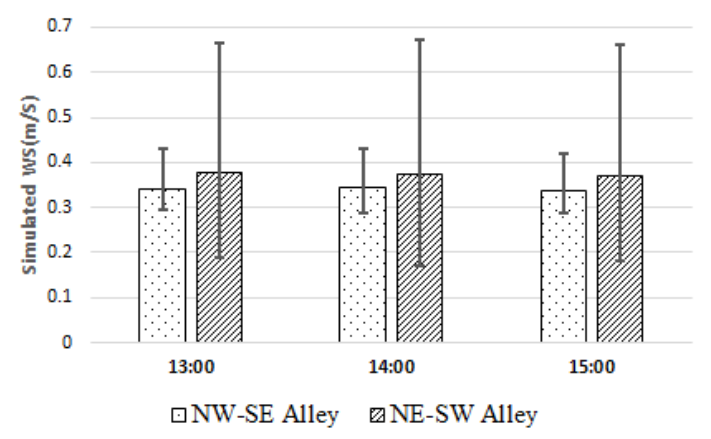

b.

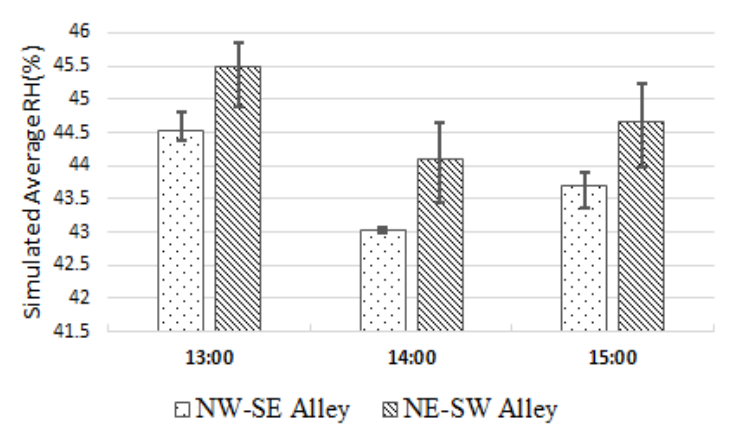

d.

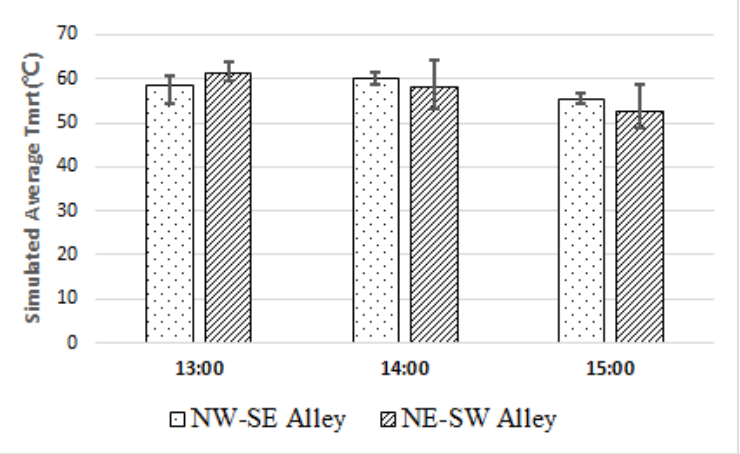

Fig.6. A verage microclimate parameters in alleys of both orientations during 13:00-15:00: (a) Ta, (b) RH, (c) WS, (d) Tmrt.

\subsection{Correlation analysis of the morphology of alleys with microclimate parameters}

The correlation analysis between the spatial morphology of alleys and microclimate parameters was conducted to analyse their relationship (see Table 5).

In NW-SE alleys, the Ta significantly correlated with $\mathrm{SVF}, \mathrm{W}$, and $\mathrm{H} / \mathrm{W}$. Specifically, Ta is positively correlated with SVF and $\mathrm{W}$ and negatively correlated with $\mathrm{H} / \mathrm{W}$. It means the lower building height and the wider alleys may result in higher temperature due to a lower ratio of sky obscuration. RH has a significantly negative correlation with $\mathrm{SVF}$ and $\mathrm{W}$ and a positive correlation with $\mathrm{H} / \mathrm{W}$. Thus, the more spacious the alley is, the less relative humidity is. Tmrt and PET (human thermal comfort index) are significantly correlated with $\mathrm{SVF}, \mathrm{W}$, and $\mathrm{H} / \mathrm{W}$. In other words, the wider alleys can receive more solar radiation, and the human body feels hotter. At the same time, Tmrt and PET are negatively correlated with the building height on the south side. Therefore, the taller buildings on the south side can 
reduce the Tmrt and PET values, while these two values do not correlate with the building height on the north side. However, wind speed has little correlation with $\mathrm{H} / \mathrm{W}$.

In the NE-SW alley, the SVF has a significant effect on all microclimate parameters. The $\mathrm{W}$ and $\mathrm{H} / \mathrm{W}$ have significantly positive effects on the Tmrt and PET values,

Table5. Results of correlation analysis between the morphology of alleys with microclimate parameters and PET.

\begin{tabular}{cccccc}
\hline $\begin{array}{c}\text { The spatial } \\
\text { morphological } \\
\text { indexes }\end{array}$ & $\mathrm{Ta}\left({ }^{\circ} \mathrm{C}\right)$ & $\mathrm{RH}(\%)$ & $\mathrm{WS}(\mathrm{m} / \mathrm{s})$ & $\mathrm{Tmrt}\left({ }^{\circ} \mathrm{C}\right)$ & $\mathrm{PET}\left({ }^{\circ} \mathrm{C}\right)$ \\
\hline $\mathrm{SVF}$ & $0.195^{*}$ & $-0.195^{*}$ & 0.181 & $0.249^{*}$ & 0.167 \\
$\mathrm{~W}(\mathrm{~m})$ & $0.280^{* *}$ & $-0.285^{* *}$ & 0.009 & $0.348^{* *}$ & $0.345^{* *}$ \\
$\mathrm{H} / \mathrm{W}$ & $-0.251^{*}$ & $0.253^{*}$ & 0.063 & $-0.416^{* *}$ \\
$\mathrm{Hn}$ & 0.107 & -0.107 & 0.177 & 0.091 & $-0.405^{* *}$ \\
$\mathrm{Hs}$ & 0.005 & -0.006 & 0.179 & $-0.357^{* *}$ & $-0.369^{* *}$ \\
\hline $\mathrm{SVF}$ & $0.218^{*}$ & $-0.212^{*}$ & $0.309^{* *}$ & $0.475^{* *}$ & $0.371^{* *}$ \\
$\mathrm{~W}(\mathrm{~m})$ & -0.081 & 0.088 & -0.048 & $0.325^{* *}$ & $0.404^{* *}$ \\
$\mathrm{H} / \mathrm{W}$ & 0.010 & -0.010 & -0.010 & $-0.204^{*}$ & $-0.263^{* *}$ \\
$\mathrm{HW}$ & $-0.396^{* *}$ & $0.395^{* *}$ & $-0.359^{* *}$ & $-0.383^{* *}$ & $-0.236^{* *}$ \\
$\mathrm{He}$ & $-0,111$ & 0.125 & $0.211^{*}$ & $0.207^{*}$ & 0.101 \\
\hline
\end{tabular}

\section{Conclusion}

This study investigated the influence factors of the thermal environment in the DLWX historical district, and the main findings are as follows:

1) Compared with NE-SW alleys, the overall thermal environment of NW-SE alleys is worse because its orientation is aligned to the sun's elevation angle, Ta, RH, WS, and MRT among the NW-SE alleys with different widths is smaller than those among the NE-SW alleys from 13:00 to 15:00.

2) Among all the alley morphology factors, the SVF and alley width have positive effects on the PET value, which means the more open and wider the alley is, the less thermal comfort of the space is.

3) At NW-SE alleys, the H/W and WS have negative effects on PET value, and at the same time, at NE-SW alleys, the $\mathrm{H} / \mathrm{W}$ and $\mathrm{Hw}$ have negative effects on PET value. It means that a high aspect ratio and taller buildings on the side of the afternoon solar incidence can block the solar radiation, thereby creating a more comfortable space.

Based on the above analysis, it was found that the thermal comfort of all alleys in DLWX is generally overheated in summer and lasts for a long time, so the current situation where urban construction can hardly change, designers can reduce the thermal stress and increase the cool area by changing the SVF. Since the thereby receives more solar radiation. The deviation of thermal comfort needs to be improved urgently. In the but not the Ta, RH, and the wind speed. Furthermore, the building height on the west side of the alley shows significant effects on all the microclimatic parameters, this means the taller building on that side can block more solar radiation, thereby the reduces the Tmrt and PET values.
SVF is closely related to the thermal comfort of the two approaches to the alley, the designer can add plant gallery frames growing such as grape, towel gourd, and vines to provide shade and summer escape in summer. Secondly, because the height of the building on certain sides is related to the microclimate variations, shading facilities can set at the buildings, for example, the building walls on the north side of the NW-SE alley and the east side of the NE-SW alley.

The findings of this study may provide a reference for improving the thermal comfort in DLWX, quantitative researches of the heat mitigation strategies (such as shading facilities, and vertical greening) should be carried out in the further stages.

\section{ACKNOWLEDGMENTS}

This work was supported by the Research Project of Philosophy and Social Sciences in Jiangsu Universities (No. 2020SJA2045) and the Post-doctoral Research Fund of Jiangsu Province (No. 2020Z274).

\section{References}

1. Kanchane, K. Steemers, Adaptive comfort assessments in urban neighbourhoods: Simulations of a residential case study from London. Energy \& Buildings 202, (2019).

2. L. Dayi et al., A review of mitigating strategies to improve the thermal environment and thermal 
comfort in urban outdoor spaces. Science of the Total Environment 661, (2019).

3. G. G. Whitman S, Donoghue ER, et al., Mortality in Chicago attributed to the July 1995 heat wave. Am J Public Health 87(9), 1515-1518 (1997).

4. J. Y. Son, J. T. Lee, G. B. Anderson, M. L. Bell, The impact of heat waves on mortality in seven major cities in Korea. Environ Health Perspect 120, 566571 (2012).

5. Å. Daniel Oudin, B. Forsberg, Rocklöv Joacim, Heat wave impact on morbidity and mortality in the elderly population: A review of recent studies. Maturitas 69, (2011).

6. T. R. Oke, Boundary layer climates. (Routledge, 2002).

7. Y. Xiong, Y. Yan, Effects of spatial design and microclimate on human thermal comfort in the region south of the Yangtze River:a case study of old street in Gaochun,Nanjing. Journal of Nanjing Forestry University(Natural Sciences Edition) 45, 219-226 (2021).

8. Y.Yang, X.1. Tang, Q.Y. Ji, M. X. Sun, Mumerical simulation of the microclimate environment in typical historic blocks of Nanjing Based on ENVImet. Journal of Suzhou University of Science and Technology Engineering and Technology edition 31, 33-40 (2018).

9. R.B. Fan, H.Y. Li, D.Yuan, Research on Ecological Micro-climate in Historic District Based on Ecotect:The Case of Sanxuejie Historic District in Xi'an. Huazhong Architecture 34, 100-105 (2016).

10. X.zhang, Shandong Jianzhu University, (2019).

11. Shuang He, North China University of Technology, (2019).

12. T.Q. Liu, R. Han, Research on the Protection and Renewal of Historical Cultural Block under the Background of Aging -- A Case Study of Dalong Wang Lane in Zhenjiang City. Art Panorama, 107109 (2019).

13. Statistical Yearbook of Zhenjiang, china statistics press, beijing, 2010-2019).

http://tjj.zhenjiang.gov.cn/tjj/tjnj1/xxgk_list.shtml

14. C. Liang, Edward, Simulation of the effect of downtown greenery on thermal comfort in subtropical climate using PET index: a case study in Hong Kong. Architectural Science Review 56, (2013).

15. F. Ali-Toudert, H. Mayer, Effects of asymmetry, galleries, overhanging façades and vegetation on thermal comfort in urban street canyons. Solar Energy 81, $742-754$ (2006).

16. M. Xuan et al., The study on outdoor pedestrian thermal comfort in blocks: A case study of the Dao He Old Block in hot-summer and cold-winter area of southern China. Solar Energy 179, (2019). 